
\title{
R Reserach S Suare \\ Comparative Analysis Between Paramecium Strains with Different Syngens Using the RAPD Method
}

\section{Sonoko Matsumoto}

Yamaguchi University

\section{Kenta Watanabe}

Yamaguchi University

Akiko Imamura

Yamaguchi University

Masato Tachibana

Yamaguchi University

Takashi Shimizu

Yamaguchi University

Masahisa Watarai ( $\nabla$ watarai@yamaguchi-u.ac.jp )

Yamaguchi University https://orcid.org/0000-0003-3477-3135

\section{Research Article}

Keywords: Paramecium, RAPD analysis, syngen, mating type

Posted Date: May 27th, 2021

DOl: https://doi.org/10.21203/rs.3.rs-555788/v1

License: (c) (i) This work is licensed under a Creative Commons Attribution 4.0 International License.

Read Full License 


\section{Abstract}

Paramecium spp. is types of free-living protists that live in freshwater environments. They are ciliates with high motility and phagocytosis and have been used to analyze cell motility and as a host model for pathogens. Besides such biological characteristics, apart from the usual morphological and genetic classification of species, the existence of taxonomies (such as syngens) and mating types related to Paramecium's unique reproduction is known. In this study, we attempted to develop a simple method to identify Paramecium strains, which are difficult to distinguish morphologically, using random amplified polymorphic DNA (RAPD) analysis. Consequently, we can observe strain-specific band patterns. We also confirm that the presence of endosymbiotic Chlorella cells affects the band pattern of P. bursaria. Furthermore, the results of the RAPD analysis using several P. caudatum strains with different syngens show that it is possible to detect a band specific to a certain syngen. By improving the reaction conditions and random primers, based on the results of this study, RAPD analysis can be applied to the identification of Paramecium strains and their syngen confirmation tests.

\section{Full Text}

Due to technical limitations, full-text HTML conversion of this manuscript could not be completed. However, the manuscript can be downloaded and accessed as a PDF.

\section{Figures}



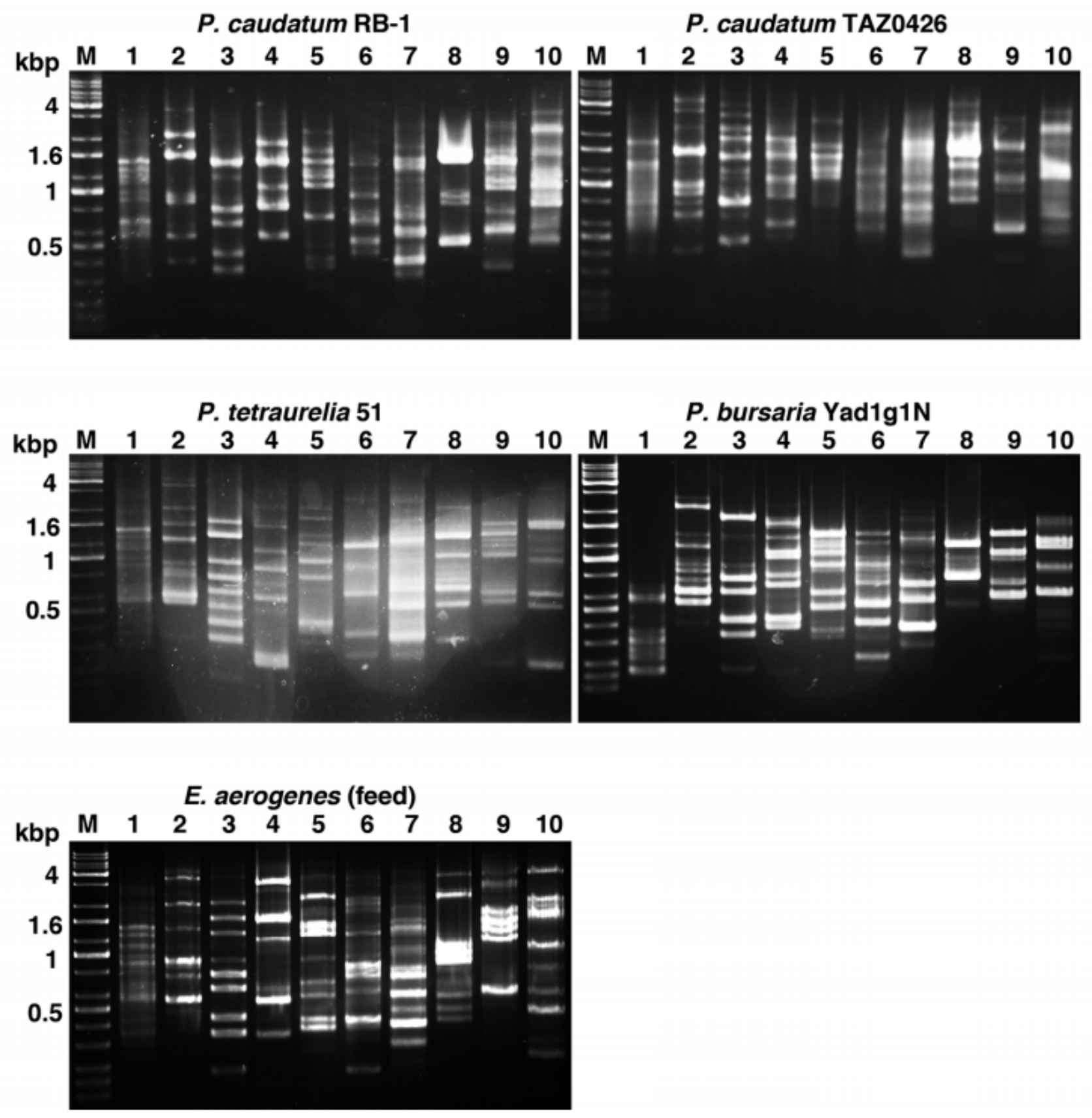

Figure 1

RAPD reaction products using primers $1-10$ separated in an agarose gel. 


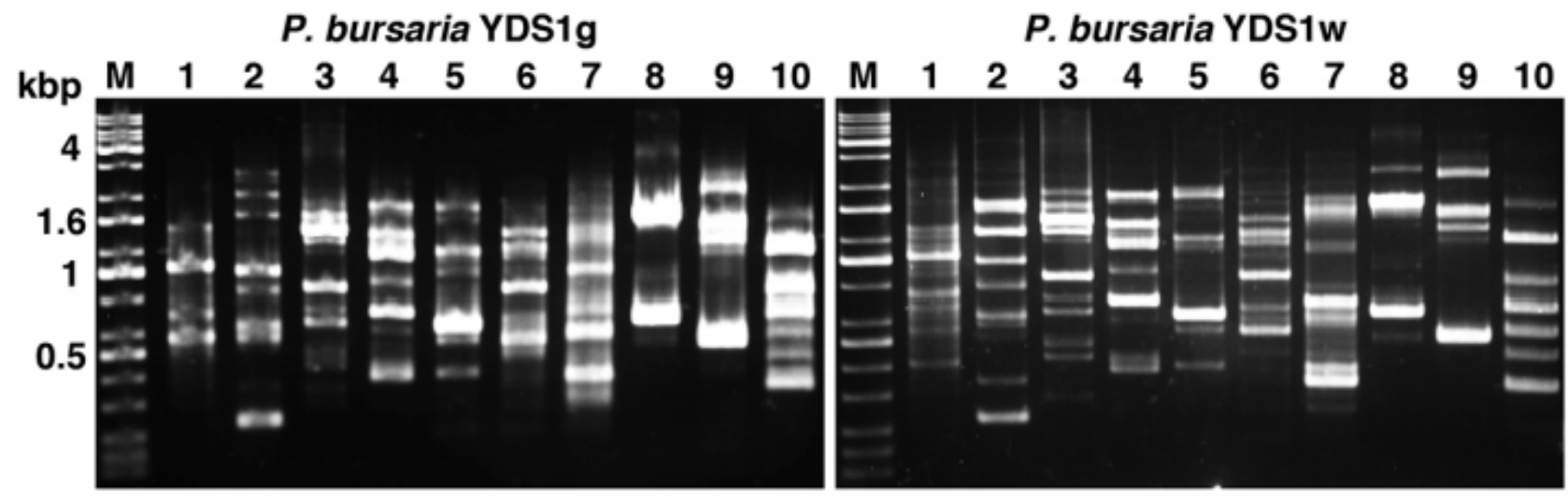

\section{P. bursaria HA1g}

P. bursaria HA1w

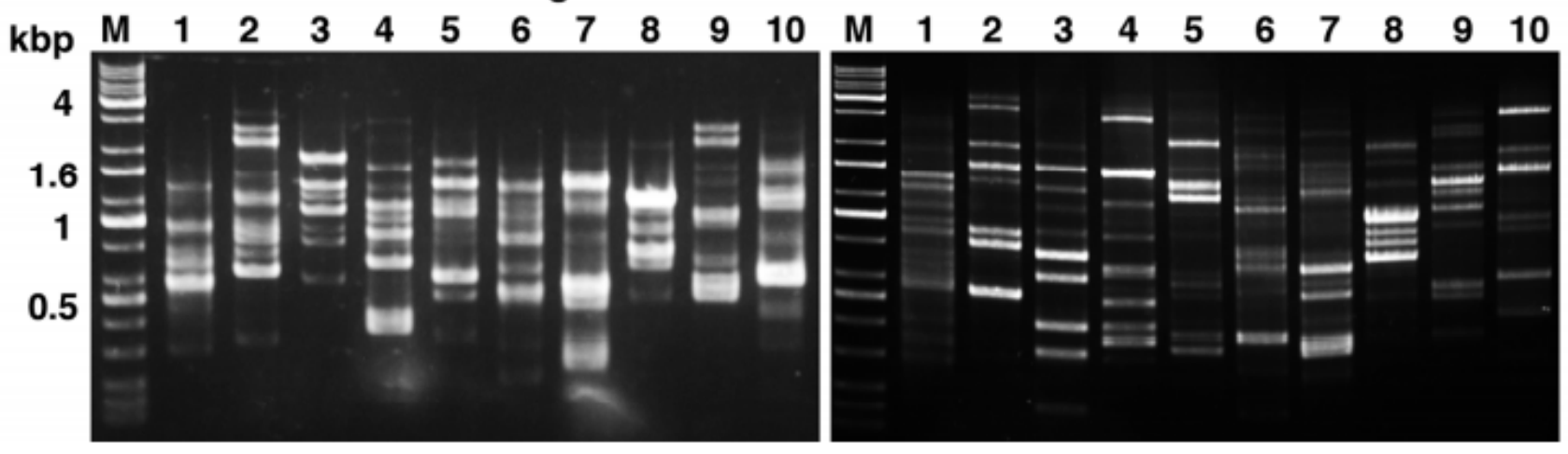

Figure 2

Differences in RAPD reaction products between P. bursaria with and without Chlorella. 


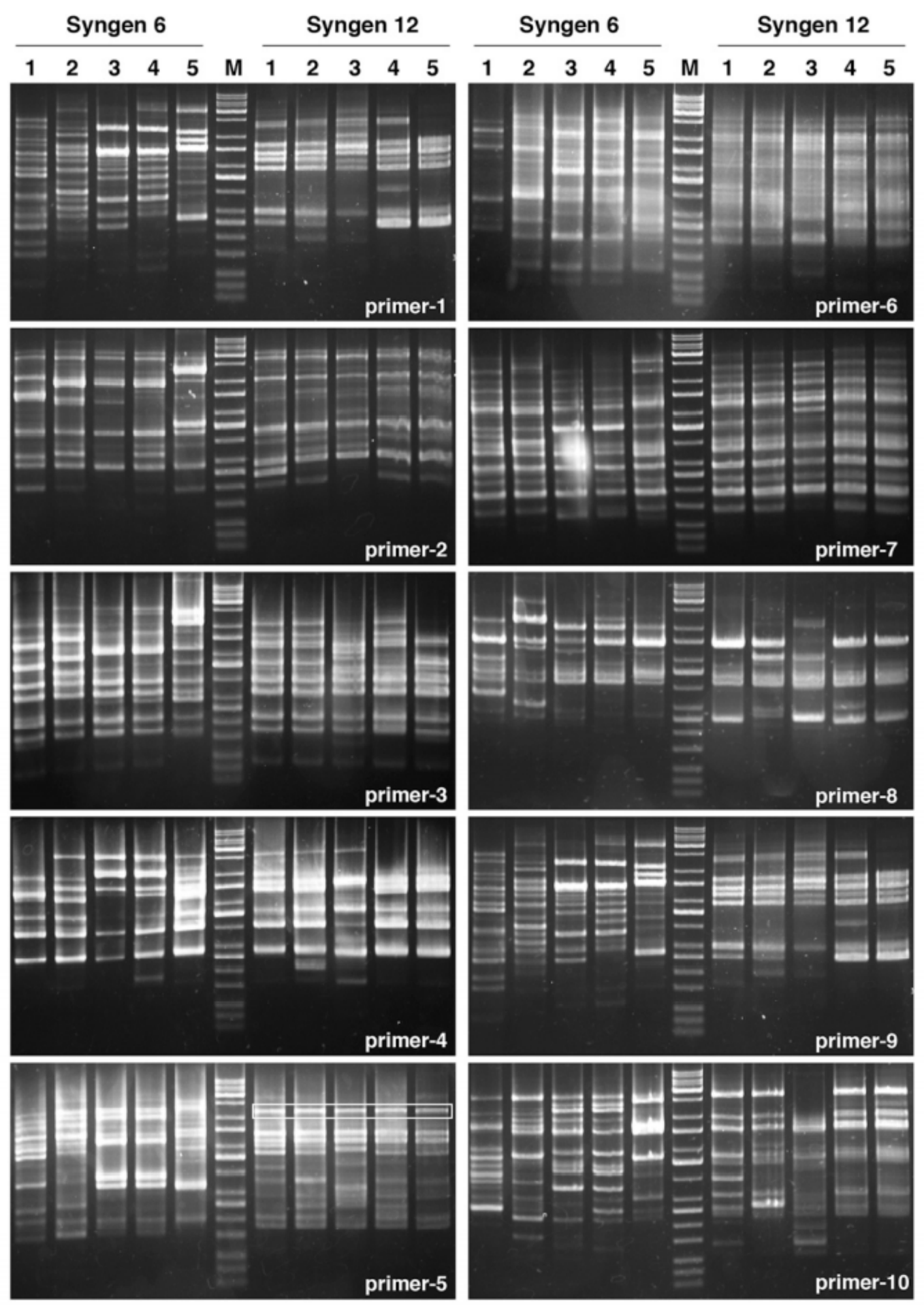

Figure 3

Comparative analysis between P. caudatum syngen 6 strains and syngen 12 strains. 


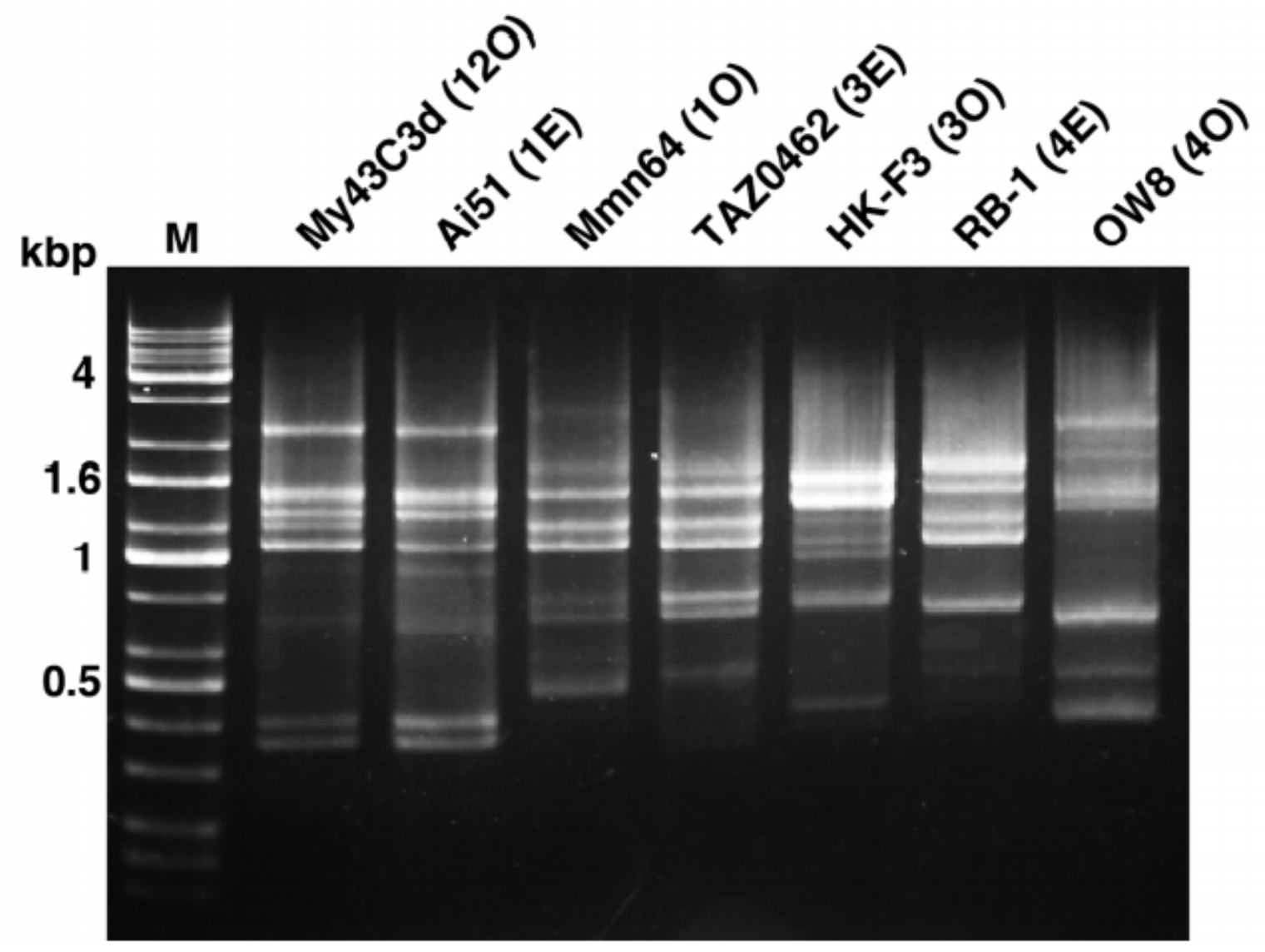

Figure 4

Evaluating the specificity of PCR product observed in P. caudatum syngen 12 strains. 